\title{
O PRINCÍPIO DE DESLOCAMENTO NA BASE DO METADESIGN
}

\author{
Carlo Franzato \\ Universidade do Vale do Rio dos Sinos - UNISINOS \\ cfranzato@unisinos.br
}

\begin{abstract}
Resumo: O conceito de metadesign é ambíguo e a literatura proporciona diversas concepções desta abordagem metodológica. $\mathrm{O}$ artigo tem como objetivo a definição de um princípio que pode ser encontrado na base dessas concepções, ou seja, o princípio de deslocamento. Este prevê a possibilidade do designer se deslocar do nível do design para o nível do metadesign, a fim de desenvolver processos projetuais sobre o próprio design. Para tanto, é apresentada a visão precursora proposta por Andries van Onck nos anos sessenta do século passado, mas ainda hoje muito influente. Como contraponto, é apresentado o caso da Alessi, empresa que trabalha com esta abordagem. A discussão das duas concepções permite definir o princípio de deslocamento.
\end{abstract}

Palavras-chave: método, processo, metadesign, metaprojeto, cenários.

\begin{abstract}
The metadesign concept is ambiguous and the literature offers different conceptions of this approach. The aim of the article is to define a methodological principle that lays at the bases of many of such conceptions, i.e. the shift principle. This principle considers the possibility that the designer shifts from the design level to the metadesign level in order to develop a design process on the same design. Thus, it is present the Andries van Onck's trailblazing vision, still influent. As a counterpoint, it is presented the case of Alessi, a company that works with this approach. The discussion of the two conceptions allows to define the shift principle.
\end{abstract}

Keywords: method, process, metadesign, scenarios.

\section{INTRODUÇÃO}

O metadesign (ou metaprojeto) é uma abordagem metodológica amplamente difundida nos países de língua neolatina e especialmente influente na tradição do design italiano e brasileiro (VAN ONCK, 1965; POLINORO, 1993; COLLINA, 2005; CELASCHI, DESERTI, 2007; MENDINI, 2007; VERGANTI, 2009; DE MORAES, 2010; VASSÃO, 2010; REYES, 2012). 
A literatura não apresenta uma visão única dessa abordagem, pelo contrário, o metadesign é um conceito que sofre muitas interpretações. Afinal, mesmo a palavra "design" é ainda objeto de numerosas interpretações e as possibilidades aumentam se Ihe adicionamos o prefixo "meta-". Já em sua origem etimológica, de fato, "meta-" é um prefixo com significado abrangente, impreciso e, portanto, ambíguo. Pode ser traduzido com as preposições "além", "entre", "com", "depois", dentre outras, remetendo a uma mudança, transformação, sucessão, transcendência ou reflexão respeito ao conceito ao qual o prefixo "meta-" se agrega. Por certo, sabemos somente que o metadesign é algo que está tão intimamente ligado ao design que não podemos nomeá-lo se não nomeando explicitamente o mesmo design, mas que ao mesmo tempo não é o design.

Este artigo tem como objetivo discutir os fundamentos do metadesign, mas não possui a ambição de clarear definitivamente este conceito. Acredita-se, aliás, que a ambigüidade do conceito e as multíplices visões que the conseguem devam ser interpretadas como uma riqueza para a disciplina, um recurso para futuros desenvolvimentos teóricos e práticos.

$\mathrm{O}$ artigo procede apresentando duas concepções de metadesign que resumem diversas posições que encontramos na literatura. Em primeiro lugar é apresentada a visão de van Onck (1965) - pioneiro na proposição do metadesign - que embasa o trabalho de diversos pesquisadores italianos e brasileiros. Sucessivamente é apresentado o caso da Alessi - empresa que pratica declaradamente o metadesign derivando da prática profissional uma segunda visão de metadesign ligada ao desenvolvimento de cenários organizacionais.

Como resultado, o artigo aponta para um princípio metodológico fundamental: o princípio de deslocamento. As duas concepções supracitadas evidenciam a possibilidade de desenvolver processos projetuais sobre o mesmo design, resultando em sistemas, ambientes, plataformas ou cenários que habilitam o design. Justamente por isso, tais processos não são situados no nível onde o design age, mas em outro nível, o nível do metadesign. Logo, o princípio do deslocamento prevê a mudança de nível do ponto de vista do designer e o desenvolvimento de processos projetuais paralelos e para além dos que ele já desenvolvia.

\section{A VISÃO DE VAN ONCK}

Designer e teórico do design, holandês, no começo da sua carreira Andries van Onck foi para a Itália para trabalhar na Olivetti junto a Ettores Sottsass. Sua atividade intelectual e docente, em 1965 leva van Onck para o Brasil para dar um curso sobre o metadesign na FAUSP (Faculdade de Arquitetura e Urbanismo da Universidade São Paulo) e na FIESP (Federação das indústrias do Estado de São Paulo). Na ocasião, a revista "Produto e linguagem" da ABDI (Associação Brasileira de Desenho Industrial) publicou um artigo onde van Onck apresentava sua visão precursora do metadesign (VAN ONCK, 1965), que ainda ecoa em trabalhos recentes de pesquisadores brasileiros (DE MORAES, 2010; VASSÃO, 2010).

A visão de van Onck é situada em um período histórico em que o pragmatismo atingia seu ápice, havia uma grande confiança na tecnologia e vibrava a esperança para a possibilidade da nova racionalidade prospectada pela computação.

As áreas tecnológicas, inclusive o design, eram atravessadas por um desejo de cientifização que levou a uma profunda reflexão sobre os métodos projetuais (JONES, 
THORNLEY, 1963). Os métodos passavam a ser desdobrados em fases, as fases em etapas, as etapas em atividades e por cada atividade era recomendado o uso de ferramentas específicas. Como resultado, os métodos eram representados graficamente por meio de modelos processuais cada vez mais sofisticados (CROSS, 2008).

Mas van Onck não seguiu este caminho, ainda se ele também acreditava que carecesse racionalidade ao design. Por exemplo, lamentava a falta de critérios objetivos na avaliação dos projetos nos concursos de design, bem como nas escolas. $\mathrm{Na}$ procura de uma solução para esse problema, orientou-se nos aspectos comunicativos dos produtos. Na opinião de van Onck, devia existir uma linguagem visual-formal que permitisse o diálogo entre projeto, produção e destinação dos produtos, uma linguagem cujos signos eram os mesmos produtos e seus detalhes. Os designers deviam estudar essa linguagem nas escolas e praticá-la na vida profissional. Justamente a capacidade de usar essa linguagem devia ser o critério para avaliar a qualidade de seus projetos. Para tanto, porém, precisava desenvolver uma metalinguagem que permitissem aos profissionais, aos alunos, aos professores e aos críticos do design de compartilhar, discutir e evoluir essa linguagem.

Para exemplificar seu ponto de vista, van Onck citava o trabalho de projetistas como Antonio Gaudí, Gerrit Rietveld e Max Bill. Nesse último caso, van Onck referia-se a um texto do livro Form (1952) em que Bill demonstrava o processo que tinha usado para configurar a forma de um espelho de toalete: nesse processo, comentava van Onck, "variando as dimensões de arcos e raios, poder-se-ia chegar a outras infinitas formas da mesma família de formas para espelhos" (1965, p. 28). Bill não havia projetado exatamente a forma de um espelho, mas um instrumento para a configuração da forma de um espelho: "com esse instrumento tinha em mão o controle das variações formais. E como nas experiências de um laboratório de física esta experiência pode ser repetida e é, portanto, comunicável" (ibid.).

Após a análise dos trabalhos dos três projetistas, van Onck sintetiza assim sua maneira de operar:

Gaudí, Bill e Rietveld saem da premissa comum de um diálogo que precede o
projeto particular. Esse diálogo inicial é mais geral e mais abstrato. Trata-se do
design dos parâmetros de um sistema visualizado por um mecanismo
composto de elementos em movimento, sejam esses pontos, linhas e planos,
ou materiais [...]. Dentro dos limites das configurações possíveis dos
elementos é escolhida aquela variação que corresponde melhor, segundo o
projetista, às exigências do caso particular. O design desta linguagem visual-
formal o chamamos de metadesign. Isto em analogia com a metalíngua,
entendendo por metalíngua a língua que nós usamos falando da língua (ibid.).

Na visão de van Onck, o processo de metadesign mantém uma natureza projetual. De fato, Max Bill evidentemente projeta seu instrumento para a configuração da forma de um espelho. Contudo, considerando o próprio design como matéria de projeto, o metadesign deve mudar de nível, deve passar do nível onde o design age para um nível que transcenda o design, onde o metadesign possa agir sobre o design. O principal princípio metodológico que van Onck propõe é essencialmente esse deslocamento de nível. Esse princípio ainda fundamenta o conceito de metadesign. 
Do design para o metadesign não muda a natureza projetual do processo, mas muda primeiramente o nível e matéria da ação projetual, logo muda seu resultado. 0 metadesign não visa ao desenvolvimento de novos produtos finitos. 0 metadesign interpreta tais produtos, acabados e estáticos, como em estado de "movimento brecado" (ibid., p. 29). O metadesign, porém, interessa-se pelo movimento em movimento, ou seja, pelo transitório, pelo provisório, pelo mutável. O metadesign interessa-se pela inapreensível possibilidade de vir a ser, não pelos possíveis estados tangíveis do ser. Por isso, van Onck identifica como resultado do metadesign um sistema que permita e favoreça o projeto (ibid., p. 28).

No zeitgeist dos anos sessenta - que culminaram com a publicação de As ciências do artificial de Herbert Simon (1969) - para van Onck, o metadesign previa a organização de certa quantidade de informação segundo regras predeterminadas (as linhas que constituem o desenho de um espelho e sua relação recíproca), mas deixando uma margem para a re-organização das mesmas (a possibilidade de variar arcos e raios). Dentro desses limites, o projeto resultava em um processo combinatório e de escolha da combinação mais satisfatória.

Sabemos que os anos setenta começaram com o grito desesperado de Chistopher Alexander - um dos protagonistas do grande desenvolvimento dos métodos de design da década anterior - o qual rejeitava todos os resultados alcançados (1971).

\section{PROJETO POR CENÁRIOS}

$\mathrm{Na}$ virada dos anos sessenta para os setenta, van Onck continua seu trabalho na direção da semiótica e não há quem se ocupe de evoluir sua visão de metadesign. De qualquer forma, visões parecidas são desenvolvidas no design, na arquitetura, no urbanismo e na engenharia, especialmente nos estudos do projeto assistido pelo computador (ver VASSÃO, 2010). Ainda, nos últimos quinze anos o metadesign voltou a ser uma temática recorrente pelo grande desenvolvimento do design generativo, do design da interação (GIACCARDI, 2005) e, mais recentemente, do open design (AVITAL, 2011; DE MUL, 2011; SAAKES, 2011; RUBINO, 2011).

Para além desses desenvolvimentos, todos ligados à informatização do design, existe outra trajetória evolutiva do metadesign que procede silenciosa na prática profissional dos designers e na vida das empresas orientadas pelo design.

Ocorre entre os anos setenta e oitenta através do trabalho de designers como Alessandro Mendini, líder do grupo Alchimia, ou de Ettores Sottsass, líder do grupo Memphis, isto é, profissionais que certamente não podem ser definidos pragmatistas. Esses designers procuram no design uma maneira para interpretar o mundo, para especular sobre o mundo e para dialogar com o mundo, muitas vezes de forma irreverente. Apesar de serem bem sucedidos, não se preocupam com a eficácia dos seus produtos e, menos ainda, com seu resultado econômico. Mesmo assim, são frequentemente apontados como grandes inovadores, tanto que Roberto Verganti fundamenta o conceito de inovação dirigida pelo design no trabalho deles.

Nas palavras de Mendini, o conceito de metadesign é explicitamente presente há mais de cinqüenta anos (1969). E justamente Mendini é um dos protagonistas de um caso de metadesign exemplar e bastante conhecido: o da empresa italiana Alessi. 
Especialmente a partir dos anos 90, Alessi começou a propor objetos que quebraram os paradigmas das utilidades domesticas, como resultado de um processo de inovação dirigida pelo design exemplar.

Em 1990, por exemplo, Alessi lançou o espremedor de frutas cítricas Juicy Salif, projetado por Philippe Starck. Como relatado por Peter Lloyd e Dirk Snelders (2003), esse é um produto com alto valor agregado, longevo e que parece não sofrer do risco das cópias, mesmo que facilmente imitável, do momento em que vem sendo produzido ininterruptamente desde então em centenas de milhares de exemplares. Os dois autores estudaram particularmente este caso para entender as suas origens criativas e explicar o seu sucesso, demonstrando a disrupção que o lançamento de Juicy Salif causou no âmbito das utilidades domesticas e o processo de apropriação pelos usuários que seguiu. Juicy Salif é tratado como um simulacro nas habitações contemporâneas, uma pequena escultura erguida aos nossos lares. Não é realmente usado para espremer frutas cítricas, mas, como apontado pelo mesmo Starck (1998), talvez possa ser usado para começar uma conversação entre a jovem esposa e a sogra.

Logo após Juicy Salif, a empresa Alessi desenvolveu uma experiência de metadesign de duração trienal, que envolveu a alta administração da organização, os seus departamentos de design e marketing, designers e outros profissionais externos. Com esta experiência a empresa definiu o novo cenário que incubaria o seu trabalho nos anos seguintes, concretizado pela linha de produtos emblematicamente chamada de Family Follows Fiction (POLINORO, 1993). Parafraseando o mote do movimento moderno Form Follows Function, a empresa o negava para seguir na sua proposta especial. Seus objetos - não mais em metal, mas em plástico colorido - assumiam formas antropomorfas ou zoomorfas para personificar os protagonistas das ficções familiares que a empresa pretendia proporcionar.

Na figura 1, por exemplo, são retratados os Unnini, "pequenos seres com duas ou quatro patas e com minúsculos furos para aspergir sal e pimenta" (POLINORO, 1993, p. 53), projetados em 1993 por Alejandro Ruiz. Com a mudança de cenário, além dos produtos da empresa, mudam também sua comunicação. 


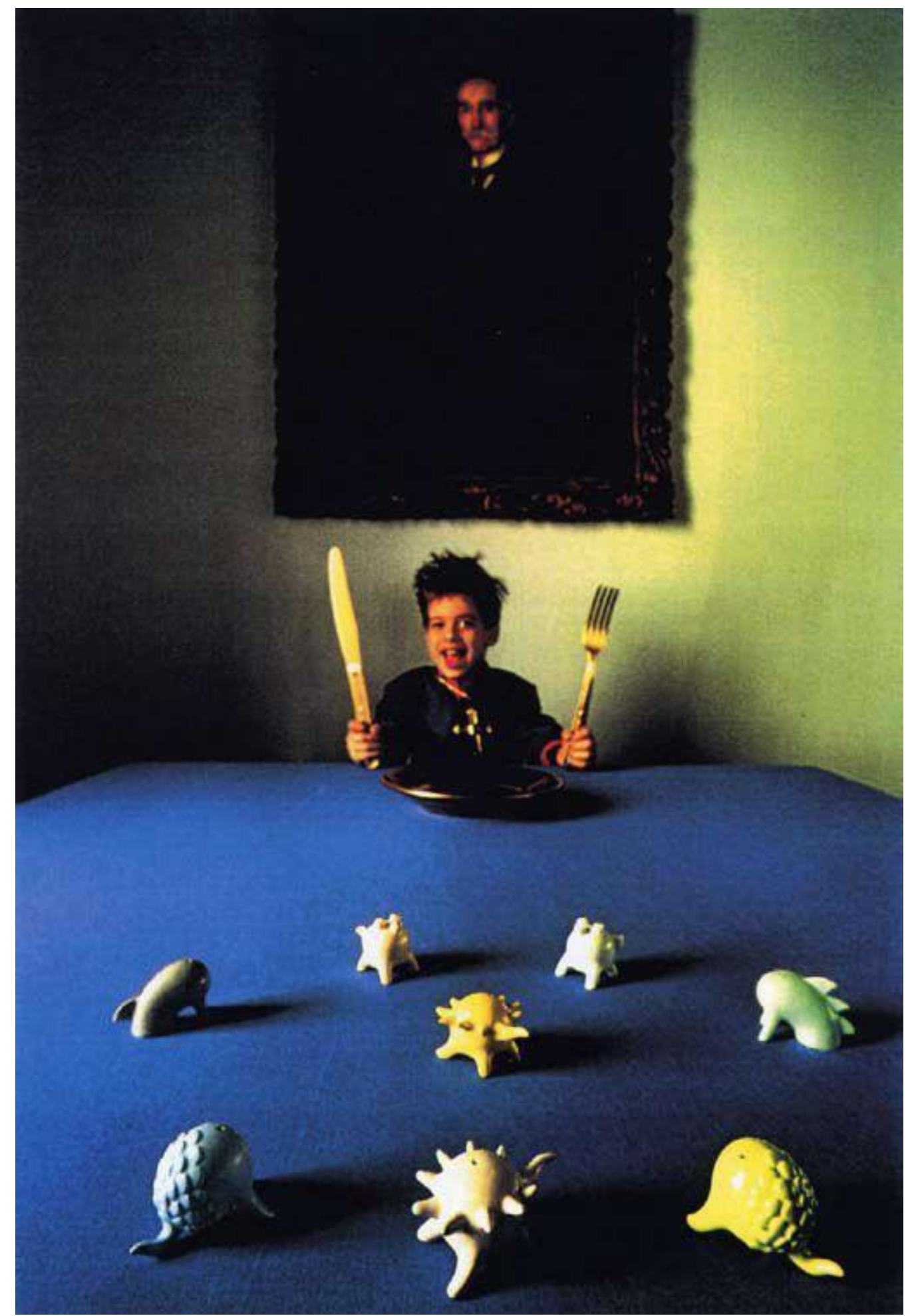

Figura 1 - Fotografia de Giacomo Giannini para retratar a série de saleiros "Unnini", projetada em 1993 por Alejandro Ruiz para Alessi (POLINORO, 1993, p. 53).

Essas experiências de metadesign não visam diretamente ao desenvolvimento de novos produtos, mas ao encontro de pontos de vista inéditos sobre o contexto de atuação competitiva das empresas e à construção de cenários empresariais alternativos. O desenvolvimento de novos produtos decorre a partir desses cenários, de maneira que os novos produtos desenvolvidos resultam em expressões dos 
conceitos conteúdos nos cenários. Segundo Alberto Alessi, diretor executivo da empresa:

\begin{abstract}
Working within the metaproject transcends the creation of an object purely to satisfy a function and necessity. Each object represents a tendency, a proposal and an indication of progress which has a more cultural resonance (apud VERGANTI, 2008: 442).
\end{abstract}

A relação entre o cenário e os produtos é de reciprocidade, pois os produtos reforçam o cenário e ajudam a interpretá-lo e evoluí-lo. E também podem contribuir para gerá-lo, como no caso de Juicy Salif que é de 1990, ou seja, anterior ao cenário Family Follows Fiction, elaborado logo em seguida e apresentado em 1993.

Portanto, cenários e produtos não estão em uma relação hierárquica, nem em uma seqüência temporal preestabelecida. Estão em dois níveis diferentes. Mas essa separação não impede que se influenciem. Pelo contrário, entre cenários e produtos existe uma influência recíproca muito fértil, cuja fertilidade depende justamente de sua separação. Na passagem dos cenários para os produtos ou dos produtos para os cenários, há um hiato que demanda um exercício interpretativo de grande teor intelectual. Demanda projeto: essa passagem não óbvia, não linear, não conseqüente faz com que o designer deva pular o hiato, jogando para frente sua ação.

\title{
CONCLUSÃO
}

Neste artigo foram apresentadas duas concepções muito diferentes de metadesign. A primeira começa com o trabalho de van Onck nos anos sessenta e hoje é retomada nos estudos ligados ao design generativo, ao design da interação e ao open design. Nessa concepção, o metadesign é entendido como um processo de design ulterior, voltado para determinar as lógicas do processo de design. Os resultados são sistemas, ambientes ou plataformas onde os próprios designers, outros designers, não designers ou até maquinas, são habilitados para elaboração de produtos.

Também a segunda concepção tem suas origens nos anos sessenta e é evoluída na prática de designers e empresas de vanguarda que estão à procura do sentido dos produtos e do design em si. Nessa concepção, o metadesign é igualmente entendido como um processo de design ulterior, mas voltado para a significação das propostas dos designers e das empresas, motivando sua ação. Os resultados são cenários em contínua evolução, que fomentam uma atitude especulativa nos designers e nas empresas, e mantém aberto o diálogo com a sociedade.

Em ambos os casos, o metadesign caracteriza-se por um deslocamento em relação ao design. Esse deslocamento pode ser assumido como o princípio metodológico que fundamenta o metadesign.

Com isso, se propõe o metadesign como uma abordagem metodológica que não fica presa a procedimentos projetuais específicos. Não existe uma sequência de passos predeterminada que permita evoluir um processo de metadesign. Onde há design, qualquer procedimento seja usado, há metadesign se o designer intencionalmente se desloca de nível e desenvolve um processo de design ulterior, exaltando a inteligência e a criatividade que são próprias do design. 


\section{AGRADECIMENTOS}

O autor agradece o apoio da fundação de amparo à pesquisa do estado do rio grande do sul (FAPERGS). Este artigo é um dos resultados da pesquisa financiada pelo programa pesquisador gaúcho de 2012.

\section{REFERÊNCIAS}

ALEXANDER, Christopher. The State of the Art in Design Methods. DMG Newsletter, v. 5, n. 3, 1971.

AVITAL, Michel. The generative bedrock of open design. In: VAN ABEL, Bas et al. (org.). Open Design Now: Why Design Cannot Remain Exclusive. Amsterdam: BIS publishers, 2011. Disponível em: http://opendesignnow.org/index.php/article/the-generativebedrock-of-open-design-michel-avital/. Acesso em 4 mar. 2014.

BILL, M. Form: a balance sheet of mid-twentieth century trends in design. Basel: Verlag Karl Werner, 1952

CELASCHI, Flaviano; DESERTI, Alessandro. Design e innovazione: strumenti e pratiche per la ricerca applicata. Roma: Carocci Editore, 2007.

COLLINA, Luisa. Design e Metaprogetto. Teorie, strumenti, pratiche. Milano: Edizioni POLI.design, 2005.

CROSS, N. The Design Process. In: CROSS, N. Engineering design methods. Strategies for product design. Chichester: Wiley, 2008, pp. 29-42.

DE MORAES, Dijon. Metaprojeto: o design do design. São Paulo: Blücher, 2010.

DE MUL, Jos. Redesigning design. In: VAN ABEL, Bas et al. (org.). Open Design Now: Why Design Cannot Remain Exclusive. Amsterdam: BIS publishers, 2011. Disponível em: $\quad$ http://opendesignnow.org/index.php/article/redesigning-design-jos-de-mul/. Acesso em 4 mar. 2014.

GIACCARDI, Elisa. Metadesign as an Emergent Design Culture. Leonardo, v. 38, n. 4, 2005, p. 342-349. Disponível em: http://trans-techresearch.net/wpcontent/uploads/2012/03/giaccardielisa.pdf. Acesso em 4 mar. 2014.

JONES, John Chris; THORNLEY, Denis Glyn (org.). Conference on Design Methods. Oxford: Pergamon, 1963.

LLOYD, Peter; SNELDERS, Dirk. What was Philippe Starck thinking of? Design Studies, v. 24, n. 3, pp. 237-253, 2003.

POLINORO, Laura (org.). F.F.F. Family Follows Fiction, Workshop 1991/1993. Crusinallo: Fratelli Alessi Omegna, 1993.

REYES, P. Projetando pela exterioridade do projeto. Strategic Design Research Journal, v. $5, \quad$ n. 2, 2012, p. 91-97. Disponível em: http://www.unisinos.br/ diversos/revistas/ojs/index.php/sdri/article/view/sdri.2012.5 2.05. Acesso em 4 mar. 2014.

RUBINO, Sara Córdoba et al. (org.). Meta products. Meaningful design for our connected world. Amsterdam: BIS, 2011, pp. 19-21; Disponível em: http://www.metaproducts.nl/book/introduction/introduction. Acesso em 4 mar. 2014. 
SAAKES, Daniel. Ikea hackers. In: VAN ABEL, Bas et al. (org.). Open Design Now: Why Design Cannot Remain Exclusive. Amsterdam: BIS publishers, 2011. Disponível em: http://opendesignnow.org/index.php/case/ikea-hackers-daniel-saakes/. Acesso em 4 mar. 2014.

STARCK, P. Starck Speaks. Politics, Pleasure, and Play. Harvard Design Magazine, verão, $1998 . \quad$ Disponível em: http://www.gsd.harvard.edu/research/publications/prizes/design arts initiative/starc klecture.html. Acesso em 4 mar. 2014.

VAN ONCK, A. Metadesign. Produto e linguagem, v. 1, n. 2, 1965, pp. 27-31. Disponível em:

http://www.docvirt.com/Wl/hotpages/hotpage.aspx?bib=Bib Redarte\&pagfis=2175\& pesq=\&url=http://docvirt.com/docreader.net. Acesso em 4 mar. 2014.

VASSÃO, Caio Adorno. Metadesign. Ferramentas, estratégias e ética para a complexidade. São Paulo: Blucher, 2010.

VERGANTI, Roberto. Design Driven Innovation: Changing the Rules of Competition by Radically Innovating what Things Mean. Boston: Harvard Business Press, 2009.

VERGANTI, Roberto. Design, Meanings, and Radical Innovation: A Metamodel and a Research Agenda. Journal of Product Innovation Management, v. 25, n. 5, pp. 436456, 2008. 